\title{
Establishment of Reference Intervals for Fasting and Nonfasting Serum Lipid Profile from Healthy Population in Mangaluru, Karnataka, India
}

\author{
Deepti S Ireshanavar ${ }^{1}$, Sukanya Shetty ${ }^{2}$, Ashalatha Rao ${ }^{3}$, Vidya S Patil ${ }^{4}$, Vijayetha P Patil ${ }^{5}$, Alagilwada S Shilpasree ${ }^{6}$
}

\begin{abstract}
Commonly the reference values used in most of the laboratory are based on the western population. These usually do not have similarity with the Indian population; this is seen especially in case of the lipid profile. Clinicians all over the world use these reference values to interpret the results obtained in patients, it should correctly impersonate the defined population having close comparison with the patient coming for investigation. ${ }^{1}$ There is no well documented evidence for the establishment of reference levels for lipids parameters for the Indian population, so there is a need for large scale study on lipid profile of Indian population. ${ }^{2}$

Materials and methods: This is a cross-sectional study, including 200 subjects in total (according to CLSI guidelines). We analyzed total cholesterol, triglycerides, HDL-cholesterol by standard methods and, LDL-cholesterol was calculated using Friedewald's formula.

Results: Median values and ranges (2.5-97.5th percentile) in $\mathrm{mg} / \mathrm{dL}$ for fasting and nonfasting total cholesterol (TC), triglycerides (TG), HDL-C, VLDL, LDL-C were: 116-239 (189), 38.8-172.4 (84), 30.9-72 (48), 7.7-42 (17.2), 59.5-177.0 (124.6), 119.9-255.1 (189), 43.9-278.6 (120), $25.5-67.1$ (44), 8.7-55.7 (24.6), 50.8-178.6 (118.6), respectively. After grouping them according to age and sex, we observed that HDL-C was significantly wider in females compared to males, TC was not significantly wider, but TG was higher in males. In the age group 39-48 years TC, TG, HDL-C and LDL-C in males were higher as compared to females of that age group.

Conclusion: Reference ranges are wider as compared to western standard, which is due to variation in diet, ethnicity, environment, etc. Hence this can be considered as the reference interval for this study population, further study is needed in a larger population.

Keywords: HDL-C, LDL-C, Lipid profile, Reference interval, Total cholesterol, Triglyceride.

Indian Journal of Medical Biochemistry (2019): 10.5005/jp-journals-10054-0124
\end{abstract}

\section{INTRODUCTION}

A reference interval may be the range of values that are deemed normal for physiological measurement of a particular type of quantity in a reference population. ${ }^{3}$

It was the International Federation of Clinical Chemistry (IFCC) who came up with the concept of reference interval mainly to avoid the problems with normal values and values obtained from an individual under clinical investigation. Clinicians compare the patient related observation with the reference values and come to a conclusion on the diagnosis of the disease, which help them to treat the patient accurately. ${ }^{4}$

The central role of the laboratory scientist is to aid the clinician, in interpreting observed values, by providing relevant reference values in a convenient and practical form. In India, reference values used in laboratories have been established in the western population. ${ }^{5}$

Reference values may be used to evaluate the state of health of individuals and populations, to identify people at risk for disease, to help in decision making in clinical medicine and to be used for various scientific purposes. ${ }^{6}$

Reference intervals are typically established by assaying specimens from a sample group of people who meet carefully defined criteria. ${ }^{7-10}$ Producing reference intervals for a general population is a major challenge, as it requires selecting the appropriate reference population and recruiting individuals who represent relevant demographic groups that meet the inclusion criteria; collecting, processing and testing specimens; and finally,
1,4-6Department of Biochemistry, SDM College of Medical Sciences and Hospital, Dharwad, Karnataka, India

2,3 Department of Biochemistry, KS Hegde Medical Academy, Mangaluru, Karnataka, India

Corresponding Author: Deepti S Ireshanavar, Department of Biochemistry, SDM College of Medical Sciences and Hospital, Dharwad, Karnataka, India, Phone: +91 9986960051, e-mail: deeptiireshanavar@ gmail.com

How to cite this article: Ireshanavar DS, Shetty S, Rao A, et al. Establishment of Reference Intervals for Fasting and Nonfasting Serum Lipid Profile from Healthy Population in Mangaluru, Karnataka, India. Indian J Med Biochem 2019;23(3):327-330.

Source of support: Nil

Conflict of interest: None

calculating reference values with possible stratification of the data into subgroups. ${ }^{11}$

Lipids are heterogeneous group of fat and fat soluble substances characterized by being water-insoluble and soluble in nonpolar solvents such as alcohol, ether, chloroform, benzene, etc.

Lipoproteins are lipid-protein complexes in which lipids are transported in blood. There is a great variation of plasma lipid levels in different populations and are usually affected by age, sex, food habits, lifestyle, socioeconomic status, races, heredity, etc.'

Lipids and lipoproteins are intimately involved in the development of atherosclerosis, which is the underlying cause of

(c) The Author(s). 2019 Open Access This article is distributed under the terms of the Creative Commons Attribution 4.0 International License (https://creativecommons. org/licenses/by-nc/4.0/), which permits unrestricted use, distribution, and non-commercial reproduction in any medium, provided you give appropriate credit to the original author(s) and the source, provide a link to the Creative Commons license, and indicate if changes were made. The Creative Commons Public Domain Dedication waiver (http://creativecommons.org/publicdomain/zero/1.0/) applies to the data made available in this article, unless otherwise stated. 
cardiovascular disease like myocardial infarction. It can also cause cerebrovascular disease and peripheral vascular disease. 3,12,13

Usually the lipid profile is done in fasting blood specimen, due to two main reasons:

- Postprandial triglycerides remain elevated for several hours after meals and are highly variable.

- The reference values for serum lipid profile have been determined on fasting blood specimen. ${ }^{1}$

Commonly the reference values used in most of the laboratory are based on the western population. These usually do not have similarity with the Indian population; this is seen especially in case of the lipid profile. Clinicians all over the world uses these reference values to interpret the results obtained in patients, it should correctly impersonate the defined population having close comparison with the patient coming for investigation. ${ }^{1}$ There is no well documented evidence for the establishment of reference levels for lipids parameters for the Indian population, so there is a need for large scale study on lipid profile of Indian population. ${ }^{2}$

\section{Aims and Овjective}

To establish the reference intervals for lipid profile in semi-urban population.

\section{Materials and Methods}

\section{Study Design}

Cross-sectional study.

\section{Sample Size}

Total of 200 subjects were included in the study (according to CLSI guidelines to establish the reference intervals). ${ }^{14}$

\section{Inclusion Criteria}

Normal healthy individuals aged between 18 years and 55 years with body mass index (BMI) between $18 \mathrm{~kg} / \mathrm{m}^{2}$ and $24.99 \mathrm{~kg} / \mathrm{m}^{2}$.

\section{Exclusion Criteria}

Patients with cardiovascular disease, diabetes mellitus, hypertension, malnutrition, renal diseases, cerebrovascular diseases, sepsis, medications, TPN, alcohol abuse, smoking, endocrine disorders, pregnancy, various storage disorders, congenital biliary atresia, dyslipidemia, obesity, strenuous exercise, HRT.

\section{Methods}

- Anthropometric measurements: height was measured in centimeters without shoes by standard procedure and weight was measured in kilograms and used for calculation of BMI.

- Method of sample collection: $2 \mathrm{~mL}$ of blood sample was collected from seated subjects from the antecubital vein with aseptic precautions with $2 c c$ syringe in plain red-topped vacutainer tubes containing clot activator. We collected two samples from each individual, one sample was collected after 8-12 hours of fasting and second sample was collected in nonfasting state (i.e., random sample). We separated the serum by centrifugation at 3,000 rpm for 5 minutes within 1 hour and lipid profile parameters were assayed in duplicate to minimize analytical variation ${ }^{15}$ in Roche Hitachi (902) autoanalyzer.

- Quality control: the analyzer was calibrated with materials provided by the Bio-Rad. Changes in calibration curve and specificity of the analytical method were detected by using a number of accuracy control specimens, at both normal (level I) and pathological (levels II) of concentration, for the lipid profile analytes. During the study there were no change in the equipment, reagents, calibration standards, and controls. The following parameters were analyzed:

- Cholesterol by CHOD-PAP method

- Triglycerides by glycerophosphate oxidase method

- HDL-cholesterol by direct/homogeneous assay

- LDL-cholesterol was calculated using Friedwald's formula

\section{Statistical analysis}

- SPSS version 17 was used

- Mean \pm SD was calculated

- 2.5-97.5th percentiles were calculated

- Total cholesterol, LDL-C were calculated by parametric method to determine the 2.5-97.5th, triglyceride, HDL-C, VLDL were calculated by nonparametric method-based Mann-Whitney's ranked data

- Comparison between male and females was done using student " $t$ " test

- $p$ value $<0.05$ is taken as significant

\section{Results}

Median values and ranges (2.5-97.5th percentile) in $\mathrm{mg} / \mathrm{dL}$ for fasting and nonfasting TC, TG, HDL-C, VLDL, LDL-C were: 116-239 (189), 38.8-172.4 (84), 30.9-72 (48), 7.7-42 (17.2), 59.5-177 (124.6), 119.9-255.1 (189), 43.9-278.6 (120), 25.5-67.1 (44), 8.7-55.7 (24.6), 50.8-178.6 (118.6), respectively as shown in Table 1 and Figure 1. After grouping them according to age and sex, we observed that the reference range for $\mathrm{HDL}-\mathrm{C}$ was significantly wider in females when compared to males, reference range for TC was wider but not significant, but TG was higher in males as shown in Tables 2 and 3 and Figure 2.

In the age group 39-48 years TC, TG, HDL-C and LDL-C were higher in males as compared to females of that age group (data not shown).

\section{Discussion And Conclusion}

Health and disease can be distinguished by accurate and reliable reference intervals of a clinical laboratory testing. ${ }^{16}$ Reference interval is crucial for disease screening, diagnosis, monitoring, progression and treatment efficacy. Clinical chemistry reference

Table 1: Reference ranges for fasting and nonfasting lipid profile obtained in our total study population

\begin{tabular}{llllll}
\hline & $T C$ & $T G$ & $H D L$ & VLDL & \multicolumn{1}{c}{ LDL } \\
\hline $\begin{array}{l}\text { Reference interval } \\
\text { (fasting lipid profile) }\end{array}$ & $109-239(189)$ & $38.8-172.4(84)$ & $30.9-72(48)$ & $7.7-42(17.2)$ & $58.6-170.4(124.6)$ \\
$\begin{array}{l}\text { Reference interval } \\
\text { (nonfasting lipid profile) }\end{array}$ & $119.9-255.1(189)$ & $43.9-278.6(120)$ & $25.5-67.1(44)$ & $8.7-55.7(24.6)$ & $50.8-178.6(118.6)$ \\
\hline
\end{tabular}




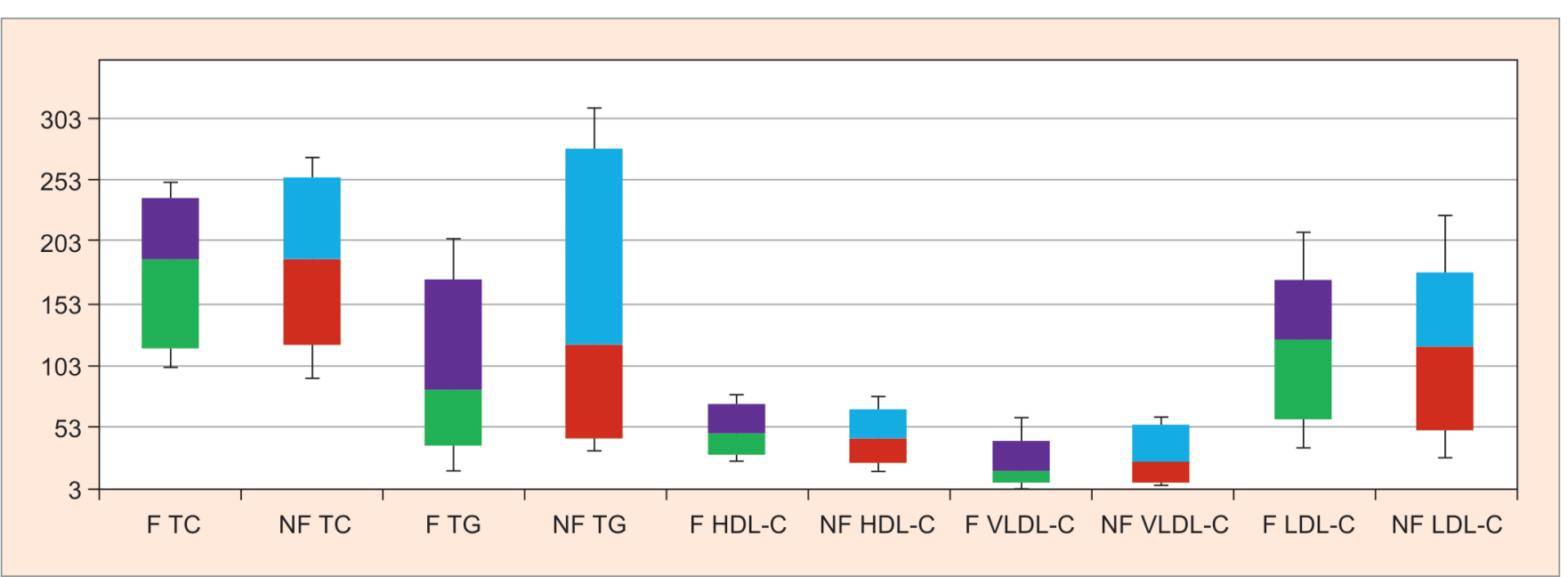

Fig. 1: Reference ranges for fasting and nonfasting lipid profile obtained in the total study population

Table 2: Reference ranges for lipid profile obtained in different age groups in our study population

\begin{tabular}{|c|c|c|c|c|c|c|}
\hline Age (years) & $\begin{array}{l}\text { No. of } \\
\text { participants (n) }\end{array}$ & $T C$ & $T G$ & $H D L$ & $V L D L$ & $L D L$ \\
\hline $18-27$ & 86 & $105-201$ (178) & $26.5-156(78)$ & $34-72.4(47)$ & $5.3-37.2(15.6)$ & $44-156.1$ (110.4) \\
\hline $28-37$ & 68 & $136-238$ (198) & $40-166$ (91) & $30-72(48)$ & $8-56.8(18.3)$ & $69.8-192.1(130.8)$ \\
\hline $38-47$ & 41 & $130-251(210)$ & $37-204$ (107) & $26.6-67.8(49.6)$ & $7.47-45.1(22.8)$ & $65.5-182.6$ (139) \\
\hline $48-55$ & 5 & $104-245$ (219) & $62-123(96)$ & $32-59.8(54.9)$ & $12.4-24.6(12.4)$ & $59.6-165.5(154.4)$ \\
\hline
\end{tabular}

Table 3: Comparison of reference ranges between males and females

\begin{tabular}{llll}
\hline Lipid profile & Males & Females & pvalue \\
\hline TC & $116-240(188.5)$ & $106-240.8(191)$ & 0.245 \\
TG & $30.3-277.7(106)$ & $38-199(79)$ & $0.001^{*}$ \\
HDL-C & $32.7-68(43.5)$ & $30-72.1(49.6)$ & $0.001^{*}$ \\
VLDL & $7.7-42(17.2)$ & $7.8-39.8(15.8)$ & $0.001^{*}$ \\
LDL-C & $59.5-177(124.6)$ & $59.8-166.9(126.4)$ & 0.047 \\
\hline
\end{tabular}

*Highly significant $p$ value

intervals are also important for identifying abnormal laboratory results and ultimately guiding patient management decisions. ${ }^{17}$

Providing relevant reference values in convenient form is the main and important role of the laboratory physician, which will help the clinician in interpreting the observed value and make a diagnosis. The reference ranges what we use in most of the Indian laboratories are the one which were established in the western population. $^{5}$

The present study aimed to establish the reference interval for the semi-urban population of Mangaluru.

Subjects selected were with normal BMI and no major difference in the diet pattern in the overall present population. Major illnesses were ruled out by clinical history.

Present study showed wider range for TC, TG, VLDL and LDL-C, as compared to the standard reference values, but HDL range was similar to standard reference value.

This might be due to different diet, climatic condition and ethnicity of the local population compared to the western population.

But some Indian studies, Durgawale et al. showed similar results. The values obtained (in $\mathrm{mg} / \mathrm{dL}$ ) for TC, TG, HDL, VLDL and LDL were $165.7 \pm 30.2,88.36 \pm 31.2,44.86 \pm 10.68,101.66 \pm 29.8$ and $18.11 \pm 7.35$, respectively. ${ }^{4}$
After grouping according to gender and age, the median and the upper range for total cholesterol, HDL-C and LDL-C concentration were higher in women in comparison to men, and triglyceride and VLDL cholesterol were higher in men than women, except in age group 38-47 years where cholesterol also is higher in males compared to women.

In present study, the reference range for HDL-C is significantly wider in females as compared to males, TC is wider in females but not significant. The TG, VLDL, and LDL-C values were higher in males as compared to females. When grouped into different age group, range for TC, TG, VLDL and LDL-C increased as the age increased except in age group 45-55 years, this could be due to less number of participants in this age group as compared to the other age group. The gradual increase can be explained by the decreased physical activity and decreased tolerance to fat intake and LPL activity and decreased clearance. ${ }^{5}$

Madhumita Das and Mauchumi Saikia did a study on the reference values of lipid profile in Assamese population in the age group of 20-80 years and concluded that cholesterol levels were in wider range in all age groups for both sexes than the reference range used in the laboratories. Ranges of TG levels observed in men in 20-60 years age group and women in 30-60 years age group were also wider than the reference range used. Ranges of $L D L$ levels were also wider in all the age groups. The HDL and VLDL ranges were almost similar to those used in laboratory.'

In another study when they grouped the study subjects according to the age and sex, they observed that, there were no appropriate differences observed between most of the groups. They also found that triglycerides in females were low and high $\mathrm{HDL}$-cholesterol when compared with male of same age. They also observed that, there was a gradual increase in cholesterol and lowdensity lipoprotein levels in the women in the age group beyond 40 years. Minor difference was observed with dietary pattern. ${ }^{17}$ 


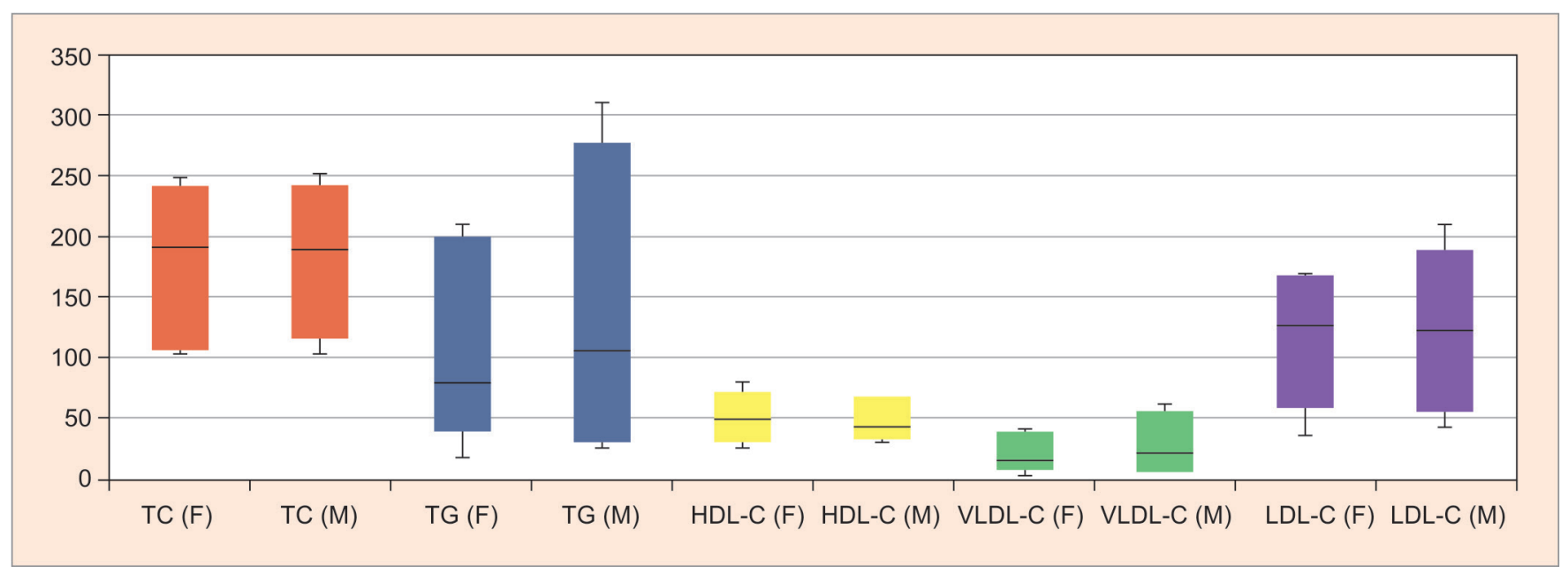

Fig. 2: Comparison of reference interval for lipid profile in females and males

Some study indicated lipid levels in their area are different from those reported by other organizations. The 75th percentile is in the normal range according to ATP-III classification, but 97.5th percentiles are above the normal range of the ATP-III class for lipid profile. $^{18}$

In our study also when considered 75th percentile was much within the normal range as compared to ATP-III class.

Compared to the western Maharashtra population mean and SD for lipid profile, our population showed much higher levels of TC, TG, HDL-C, VLDL and LDL-C.

This difference may be because of variation in dietary habits. More intake of rice and predominantly a nonvegetarian diet compared to the other population may explain the higher TC, TG, VLDL and LDL-C, other factor may be the physical activity. Higher $\mathrm{HDL}-\mathrm{C}$ can again be due to high intake of fish in diet.

\section{Conclusion}

Reference ranges are wider as compared to western standard, which is due to variation in diet, ethnicity, environment, etc. Hence this can be considered as the reference interval for this study population, further study is needed in a larger population.

Hence, this study suggests that there is requirement for a greater number of studies to establish a reference interval for all the parameters for Indian population.

\section{References}

1. Burtis CA, Ashwood ER, Bruns DE, ed. Tietz fundamentals of clinical chemistry, 6th ed., Philadelphia: Saunder Elsevier; 2008.pp. 402 and 229.

2. Das $M$, Saikia M. Stimation of reference interval of lipid profile in Assamese population. Indian J Clin Biochem 2009;24(2):190-193. DOI: 10.1007/s12291-009-0034-x.

3. Nigam PK. Serum lipid profile: fasting or non-fasting? Indian J Clin Biochem 2011;26(1):96-97. DOI: 10.1007/s12291-010-0095-x.

4. Durgawale P, Patil S. Evaluation of reference intervals of serum lipid profile from healthy population in western Maharashtra. Indian J Clin Biochem 2009;24(1):30-35. DOI: 10.1007/s12291-009-0005-2.
5. Ashavaid TF, Todur SP, Dherai AJ. Establishment of reference intervals in Indian population. Indian J Clin Biochem 2005;20(2):110-118. DOI: 10.1007/BF02867409.

6. Tandon N. Intermediary metabolism of lipids and lipid transport. In: Lipid disorders: implications and management. Tripathy BB, Das S, ed. 2002. pp. 28-32.

7. Katayev A, Balciza C, Seccombe DW. Establishing reference intervals for clinical laboratory test results is there a better way? Am J Clin Pathol 2010;133(2):180-186. DOI: 10.1309/AJCPN5BMTSF1CDYP.

8. Karita E, Ketter N, Price MA, et al. CLSI-derived hematology and biochemistry reference intervals for healthy adults in Eastern and Southern Africa. PLoS One 2009;4(2):e4401. DOI: 10.1371/journal. pone.0004401.

9. National Committee for Clinical Laboratory Standards (NCCLS). How to Define and Determine Reference Intervals in the Clinical Laboratory; Approved Guideline, 2nd ed., vol. 20, no. 13 C28-A2 Wayne, PA 2000.

10. Segolodi TM, Henderson FL, Rose CE, et al. Normal laboratory reference intervals among healthy adults screened for a HIV pre-exposure prophylaxis clinical trial in Botswana. PLoS One 2014;9(4):e93034. DOI: 10.1371/journal.pone.0093034.

11. Rustad $P$, Felding $P$, Franzson $L$, et al. The nordic reference interval project 2000: recommended reference intervals for 25 common biochemical properties. Scand J Clin Lab Invest 2004;64(4):271-284. DOI: 10.1080/00365510410006324.

12. Fauci $A S$, Kasper DL, Longo DL, , et al. ed. Principles of Internal Medicine, 18th ed., New York: McGraw Hill Companies; 2008. vol. 2.

13. Cox MM, Nelson DL. Principles of biochemistry, 5th ed., England: Sara Tenney; 1990. pp. 836-843.

14. CLSI. How to Define and Determine Reference Interval in clinical Laboratory; approved guideline, 2nd ed., vol. 20, no. 13 NCCLS document C28-A2 2000.

15. Folsom AR, Kuba K, Luepker RV, et al. Lipid concentrations in serum and EDTA-treated plasma from fasting and nonfasting normal persons, with particular regard to high-density lipoprotein cholesterol. Clin Chem 1983;29(3):505-508.

16. Horn PS, Pesce AJ. Reference intervals: an update. Clin Chim Acta 2003;334(1-2):5-23. DOI: 10.1016/S0009-8981(03)00133-5.

17. Saathoff E, Schneider P, Kleinfeldt $\mathrm{V}$, et al. Laboratory reference values for healthy adults from southern Tanzania. Trop Med Int Health 2008;13(5):612-625. DOI: 10.1111/j.1365-3156.2008.02047.x.

18. Lopez-Miranda J, Williams C, Lairon D. Dietary, physiological, genetic and pathological influences on postprandial lipid metabolism. Br J Nutr 2007;98(3):458-473. DOI: 10.1017/S000711450774268X. 